\title{
A new approach for investigation of damage zone properties in orthotropic materials
}

\author{
Mahdi Fakoor $^{\mathrm{a}^{*}}$, Mohammad Hossein Sabour ${ }^{\mathrm{b}}$ and Nabi Mehri Khansari ${ }^{\mathrm{c}}$
}

${ }^{a}$ Assistant Professor, Faculty of New Sciences and Technologies, University Of Tehran, Tehran, Iran

${ }^{b}$ Assistant Professor, Faculty of New Sciences and Technologies, University Of Tehran, Tehran, Iran

${ }^{c}$ B.Sc. student, Faculty of New Sciences and Technologies, University Of Tehran, Tehran, Iran

\begin{tabular}{l}
\hline A R T I C L E I N F O \\
\hline Article history: \\
Received March 6, 2014 \\
Accepted 23 August 2014 \\
Available online \\
24 August 2014 \\
\hline Keywords: \\
Damaged Zone \\
Orthotropic \\
Mechanical Properties \\
Numerical Method \\
Experimental Method
\end{tabular}

\begin{abstract}
A B S T R A C T
Fracture phenomenon in orthotropic materials, generally associates with region called, "damaged zone" in crack tip vicinity. In quasi-brittle materials, this area is known as fracture process zone (FPZ). This area contains a multitude of microcracks, which cause difficulties in analytical process of the region. Also, energy waste in damaged zone can affect the material fracture properties. The characteristics of damaged zone should be considered to figure out the residual strength of composite materials. It also can help to predict the value or even the direction of crack growth of orthotropic materials. So far, several efforts have been made to determine the mechanical properties of this region, but none of them (due to the immense complexity of this region) can express the behavior of this region properly. Moreover, previous approach has not been verified by new experimental and numerical results, yet. In the present study, a new approach "damaged zone simulation (DZS)" is proposed based on the experimental and numerical data, for investigating the orthotropic damaged zone properties. Comparison with existing analytical data shows the capabilities of the presented approach.
\end{abstract}

(C) 2014 Growing Science Ltd. All rights reserved.

\section{Introduction}

Composites as orthotropic materials are used in various kinds of industries like aerospace. In most cases, initiation and propagation of microcracks in composite causes the structural failures. One of the preliminary considerations in these kinds of materials is estimation of fracture residual strength. As it is well known, fracture residual strength associates with mechanical behavior of damaged zone (Damaged zone is an area that appears in crack tip vicinity). In order to figure out the residual strength of such materials, it should be concentrated on the characteristics of damage zone.

\footnotetext{
* Corresponding author.

E-mail addresses: mfakoor@ut.ac.ir (M. Fakoor) 
SYMBOLES

\begin{tabular}{ll}
\hline$E_{i}, i=L, R, T$ & Young's moduli in the i direction \\
$\bar{E}, \bar{K}, \bar{v}, \bar{G}$ & Elastic moduli of damage zone, \\
$v$ & Poisson's ratio \\
$V$ & Volume \\
$t$ & Thickness \\
$E L, E R, E T$ & Elasticity modulus in the L,R,T direction \\
$E D, G D, K D$ & Elasticity, Shear, Bulk Modulus of Damaged Zone \\
\hline
\end{tabular}

Fibrous materials have a damage zone around the crack tip and their fracture is associated with this area. It is shown that damage zone (at crack tip vicinity) has multitude of microcrack in base of cohesive zone in which by enlargement of these defects, failure process is happened (Fig.1).

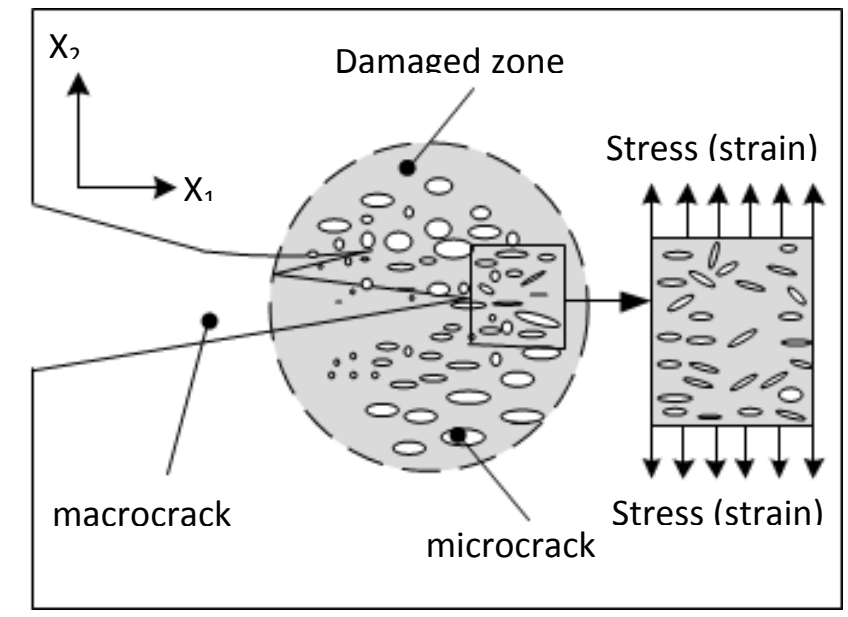

Fig. 1. Damage zone at crack tip vicinity

With respect to multitude of microcracks and cohesive basis in damaged zone, this area has complex behavior. Depend on the situation, the damaged zone can affect the rate of crack propagation and even maybe enhance it. Then, by recognizing this crucial region, fracture behavior in orthotropic materials could be estimated. Although this region has an important role in fracture of composite material, but it has been rarely modeled efficiently by numerical and experimental methods, yet. On the other hand, the considerable amount of papers has been published on behavior simulation of cracked solid with a focus on damaged zone in some of them. In 1983, Poe introduced a strain criterion for fracture of fibrous composite laminates. In that research, normal strain was reported for circumferentially notched tensile specimens (CNT) of especially orthotropic composite materials (Poe, 1983). Harris and Morris (1984) reported the fracture behavior of various thicknesses and fiber angles made of T300/5208 carbon/epoxy, laminated Graphite/Epoxy composites. Compact tension specimen (CT) and three-point-bending specimens (TPB) were used for thicker laminates and CNT specimens in different range of thicknesses.

In previous references, local damaged zone has not been considered. In 1991 a fictitious crack model proposed for investigation of damaged zone in different types of materials by Hillerborg et al. (1991). Veselý and Frantík (2014) proposed a new method for investigated of fracture in quasi-brittle materials by considering the effect of fracture process zone. According to wood properties which has various mechanical properties in different directions (depending on cutting process), it could be considered as orthotropic materials (Gohari \& Fakoor, 2010). However, some non-linear elastic 
models have been presented for composite materials, such as softwoods based on fracturing experiments (Smith et al., 2003). Also crack propagation in wood has been simulated using constant spring elements (Boström, 1992). In the present research, wood is considered as the case study. As it is well known, orthotropic materials (like balsa woods) have various applications in the most fields of engineering. $\mathrm{Wu}$ (1967) proposed an interactive equation as a criterion for mixed mode crack growth of orthotropic materials based on experimental data. A simplified fracture propagation approach can be applied to woods and composites if it is accepted that fracture propagation occurs parallel to the grain (Eq. 1). In this equation, interaction of $K_{I}$ and $K_{I I}$ has been investigated. He applied some experiments on scotch ply 1002 and Balsa wood which produced the interaction equation below $(\mathrm{Wu}, 1967)$ :

$\frac{K_{I}}{K_{I c}}+\left(\frac{K_{I I}}{K_{I I c}}\right)^{2}=1$

Woo and Chow (1979) found that similar equation can also be applied for other woods. This relationship is very similar to the maximum tensile stress criterion of isotropic materials. Recently, a new analytical mixed mode fracture criterion has been presented on reinforcement microcrack damage models for wooden specimens that takes into account the fracture process zone (Gohari and Fakoor, 2010).

\section{Methods and materials}

Orthotropic materials have commonly three principal axes shown by $(1,2$, and 3$)$ symbols. These commonly symbols, can be changed depending on materials e.g. for wood specimens, the symbols identified as L, R, T which represented as radial, tangential and longitudinal directions, respectively (Fig. 2).

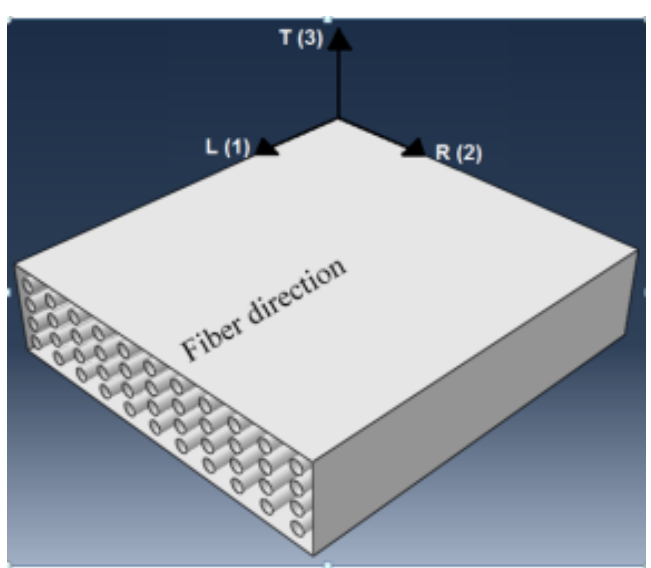

Fig. 2. Orthotropic principal coordinate system

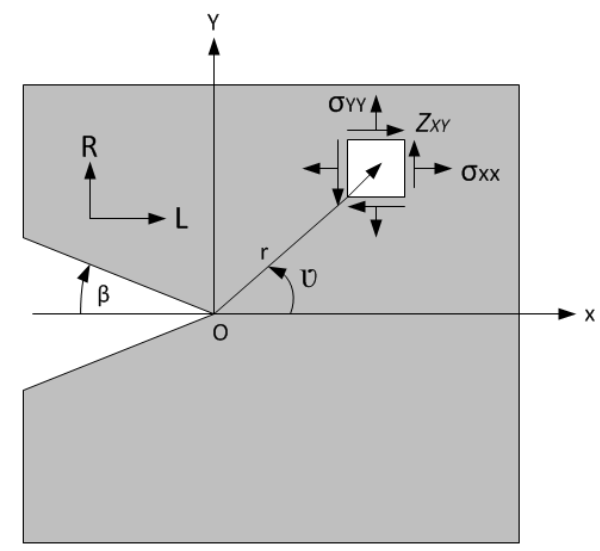

Fig. 3. Geometry for the region around the crack tip considered in the analysis of fracture in the RL system

Accordingly, there are six principal systems of crack propagation, introduced by a pair of letters, i.e. TL, RL, LR, TR, RT and LT (Gohari \& Fakoor, 2010). The first one stands for the direction of the normal to the crack plane and the second one indicates the direction of crack propagation. Out of systems of crack propagation (i.e., along wood fibers), the RL and TL systems constitute the most frequent ones, because of the particular design of timber structures. Let us consider an infinite, linear-elastic plate with a sharp notch of a wedge angle $2 \beta$ and straight edges. We shall use a system of polar coordinates $(\mathrm{r}, v)$ centered at the tip of a crack, as it is shown in Fig. 3. The 2D stress field in the notch-tip neighborhood was defined by Sih (Sih et al, 1965). 
$\sigma_{\mathrm{ij}}(\mathrm{t})=\frac{K_{I} f_{i j}(v)}{\sqrt{2 \pi r}}+\frac{K_{I} g_{i j}(v)}{\sqrt{2 \pi r}}(i, j=x, y)$

where $f_{i j}$ and $g_{i j}$ are the functions varied by angle. Therefore, a general brittle fracture criterion for structures with sharp notches can be formulated as follows (Irwin, 1957):

$K_{I, I I, I I I} \geq K_{I C, I I C, I I I C}(\beta)$

where $K_{I C}, K_{I I C}, K_{I I I C}$ are critical values of the stress intensity factors depending on the notch angle $(\beta)$. Therefore crack will propagate from a tip of notch when the actual value of the intensity factor $K_{I}, K_{I I}, K_{I I I}$ reaches a critical value. If the crack opening mode (Mode I) is considered, criterion for damaged zone adjacent to the notch-tip can be written as follows (Novozhilov, 1969):

$\max \left(\int_{0}^{d 0} \sigma_{\vartheta} d r\right) \geq d_{0} \sigma_{c}$

where $\sigma_{\vartheta}, \mathrm{r}, d_{o}$ and $\sigma_{c}$ denote, stress component normal to the crack direction, distance measured from a singular point in the stress-gradient direction, length of damage zone corresponding to microstructure and breaking stress, respectively. By substituting the equations for the stress field in the notch-tip neighborhood, (2) and (3) into (4), following relationship can be easily obtained (Irwin, 1957):

$d_{0} \leq\left(\frac{2}{\pi}\right)\left(\frac{k_{I C}}{\sigma_{c}}\right)^{2}$

where, $\sigma_{c}$ is obtained from the western white pine tensile test (Fig. 4).

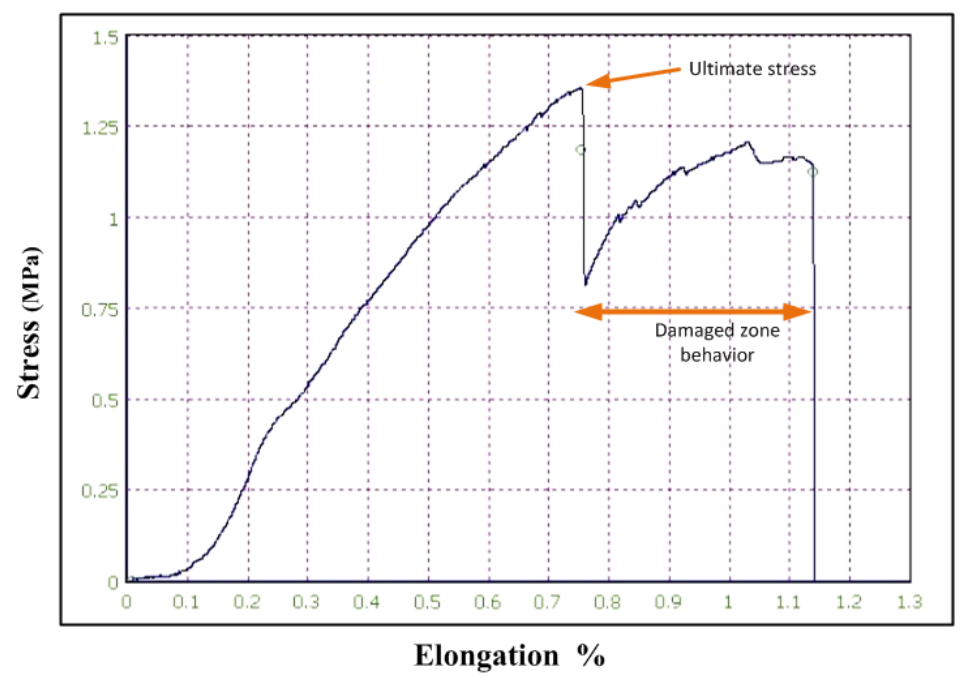

Fig. 4. Experimental stress-elongation curve for western white pine wood

As it mentioned, western white pine wood was chosen as a case study. Fracture properties of western white pine wood species have been presented in Table 1. According to the experimental data, the breaking stress $\left(\sigma_{c}\right)$ and the critical stress intensity factor $\left(K_{I C}\right)$ in RL direction obtained as 1.4 $\mathrm{MPa}$ and $260 \mathrm{kPa} \sqrt{m}$ respectively. By substituting $\sigma_{c}$ and $K_{I C}$ in (5) the length of damage zone $\left(d_{0}\right)$ calculated nearly $20 \mathrm{~mm}$.

Table 1. Fracture Properties of western white pine Wood

\begin{tabular}{ccc}
\hline & western white pine & \\
\hline direction & TL & RL \\
$K_{\mathrm{IC}}(\mathrm{kPa} \sqrt{m})$ & 250 & 260 \\
& & \\
\hline
\end{tabular}


The objective of this study is to present a new approach for investigation of mechanical properties of crack tip local damage zone, based on numerical and experimental analysis. Moreover, the relationship between mechanical behavior of damage and undamaged zone was considered. For accurate investigation, three main method i.e. analytical, experimental and numerical methods were employed. For numerical considerations first, a constant circle region by $20 \mathrm{~mm}$ diameter, considered as damaged zone (according to experimental results). Then, 1 to 200 defects created as microcrack within the area and the correlation between rate of elasticity modulus and number of microcrack were studied. For experimental consideration, western white pine wood prepared (with special configuration) and mentioned defects were created in damaged zone. Then, by increasing the amount of defects, the specimens were loaded and mechanical behavior of damaged zone was obtained. Eventually, the comparison between $\mathrm{FEM}^{1}$ and experimental results were done. The results indicated the compatibilities of new approach in comparison with previous analytical data. Moreover, a new fracture model established for FEM and experimental tensile tests similar to the Brazilian disk specimen (Fig.5). Indeed, despite the conventional Brazilian disk specimen which is loaded by diametral compression (Ayatollahi \& Aliha, 2007' Aliha \& Ayatollahi, 2008; Aliha et al., 2012, Aliha, 2013), the suggested specimen is a circular disk subjected to diametral tension. The results also denoted the capabilities of the presented approach.

\section{Model description and material properties}

As is well known, western white pine has convenience mechanical properties (it is too similar to Balsa wood). Thus, its application is very common in various industries, e.g. civil and aerospace engineering. The elastic and fracture properties of this specimen have been indicated in Table 2 .

Table 2. Elastic properties of wood species applied in this present research

\begin{tabular}{cccccccccc}
\hline Species & $\begin{array}{c}\mathrm{E}_{\mathrm{r}} \\
(\mathrm{GPa})\end{array}$ & $\begin{array}{c}\mathrm{E}_{\mathrm{T}} \\
(\mathrm{GPa})\end{array}$ & $\begin{array}{c}\mathrm{E}_{\mathrm{L}} \\
(\mathrm{GPa})\end{array}$ & $\begin{array}{c}\mathrm{G}_{\mathrm{LR}} \\
(\mathrm{GPa})\end{array}$ & $\begin{array}{c}\mathrm{G}_{\mathrm{LT}} \\
(\mathrm{GPa})\end{array}$ & $\begin{array}{c}\mathrm{G}_{\mathrm{RT}} \\
(\mathrm{GPa})\end{array}$ & $v_{\mathrm{LR}}$ & $v_{\mathrm{LT}}$ & $v_{\mathrm{RT}}$ \\
\hline $\begin{array}{c}\text { western } \\
\text { white } \\
\text { pine }\end{array}$ & 0.530 & 0.258 & 6.8 & 0.353 & 0.326 & 0.034 & 0.329 & 0.344 & 0.334 \\
\hline
\end{tabular}

As it mentioned, due to lack of standard a new test specimen, a fracture model was proposed for tensile test af damaged wood in this research. Although, Chow and Woo (1979) introduced Double Cantilever Beam (DCB) for pure mode I. however, in their method, there were no control on the number and direction of microcracks in damaged zone. Therefore, in present research, SIF increased by artificially increasing the amount of defects (microcrack) in damage zone, gradually.

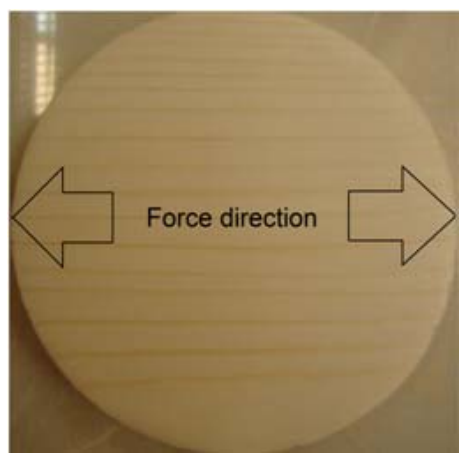

Fig. 5. A new test specimen for tensile test of orthotropic materials

\footnotetext{
${ }^{1}$ Finite element method
} 


\subsection{Analytical Method}

In the case of microcracks, a new analytical mixed mode fracture criterion based on a reinforcement microcrack damage model, has been presented for wood by Gohari and Fakoor (2010). Also previously, by considering the overall energy balance of the cracked body, effective elastic properties had been proposed (Budiansky, 1976). These effective elastic properties have been indicated in Eq. (6).

$$
\begin{aligned}
& \frac{\bar{G}}{\bar{G}}=1-\frac{8}{45}(10-7 \bar{v}) \varepsilon \\
& \frac{\bar{E}}{\bar{E}}=1-\frac{16}{45}(1+\bar{v})(5-4 \bar{v}) \varepsilon \\
& \frac{\bar{K}}{K}=1-\frac{16}{9}\left(\frac{1-\bar{v}^{2}}{1-2 \bar{v}}\right) \varepsilon
\end{aligned}
$$

where, $E, G$ and $\mathrm{K}$ are elasticity, shear and bulk modulus, respectively and also, $\bar{v}$ and $v$ are damaged and undamaged Poisson's ratio, respectively. In addition, $\varepsilon$ defines as the crack density parameter and it can be expressed as a function of Poisson's ratio (Budiansky, 1976):

$$
\bar{v}=\frac{45-8 \varepsilon+16 \varepsilon v}{16 \varepsilon(1+8 v)}+\frac{45\left(1-0.35 \varepsilon+0.032 \varepsilon^{2}+1.14 \varepsilon^{2} v+10.24 v^{2} \varepsilon^{2}-5.7 \varepsilon v^{2}\right)^{\frac{1}{2}}}{16 \varepsilon(1+8 v)}
$$

It can be found that $\bar{E}, \bar{G}$ and $\bar{K}$ are diminishing functions of $\varepsilon$. In addition, they tend to be zero at critical crack density e.g. 0.56 for scots pine wood (Gohari \& Fakoor, 2010).

\subsection{Numerical Method}

Previously, crack density parameter was obtained about 0.56 by investigating the fracture process zone of scots pine wood. It can be applied for all types of wood, analytically (Gohari \& Fakoor, 2010). On the other hand, at this critical crack density within, damaged zone lose its properties and consequently, failure is happened. Take in to account of microcrack location, random distribution of microcrack can be assumed. Moreover, with the respect of microcrack modeling complexity, a simplification has been employed, in a way that, damage zone modeled as a circle $(\mathrm{d}=1 \mathrm{~mm})$. Eventually, fracture process zone would be independent of microcracks location and their directions. In present research, the material is simulated as a lamina constituted by a linear isotropic elastic matrix under far field stress, and containing random distribution of microcracks. Also, a powerful FEM software, (i.e. ABAQUS) was used for numerical analysis. In damaged zone, geometrical configuration of microcrack and process zone can be calculated by Eq. (8).

$d=1 \mathrm{~mm}, t=8 \mathrm{~mm}$,

$V_{\text {microcrack }}=\pi \frac{d^{2}}{4} t=\pi \frac{1^{2}}{4} 8=6.28$

$d=20 \mathrm{~mm}, t=8 \mathrm{~mm}$,

$V_{\text {damaged zone }}=\pi \frac{d^{2}}{4} t=\pi \frac{20^{2}}{4} 8=2512$

where, $t$ and $d$ stands for thickness and diameter, respectively. Hereby, three numerical stages, were considered including, preprocess, process, and post process (Barbero, 2007). At the first stage, material property, loading and meshing was studied. At the second and third one, problem was solved and the results were verified. In addition, Tri-mesh structure CPS $3^{2}$ was considered for meshing, as two different mesh sizes accounted for damaged zone.

\footnotetext{
${ }^{2}$ 3-node linear triangle
} 


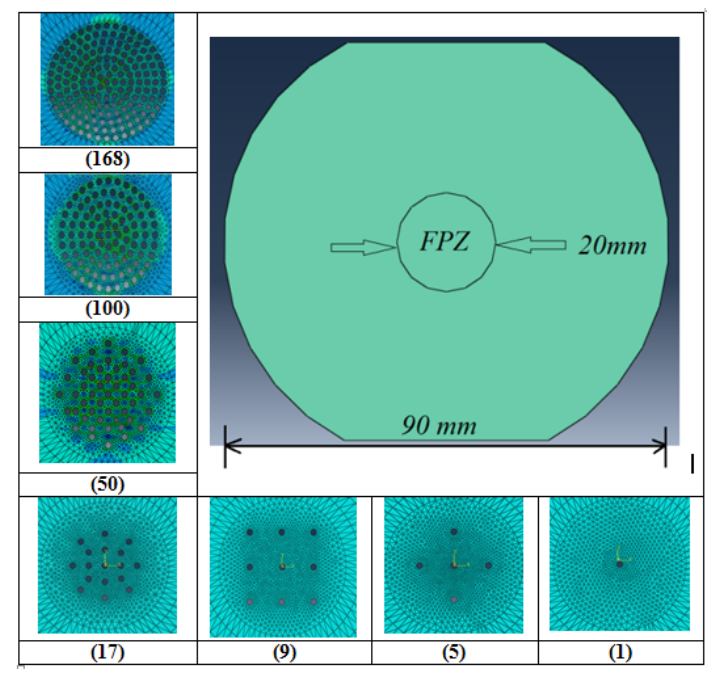

Fig. 6. FEM model of microcrack in damaged zone Fig.7. Path definition for stress and strain evaluation

By defining some path from center of damaged zone in to its boundary (Fig.7), the maximum and minimum amount of strain and stress, obtained (post process). The paths could be perpendicular or parallel to the direction of applied loads and fibers. Consequently, average of strain and stress was evaluated and the effective modulus of process zone (i.e. elasticity, bulk, and shear modulus) was defined as the course of crack density parameters (Table. 3 ).

Table 3. Mechanical behavior of damage zone in the course of crack density parameters (numerically)

\begin{tabular}{|c|c|c|c|c|c|c|c|c|c|c|}
\hline $\begin{array}{c}\mathrm{N} \\
\text { (defects } \\
\text { counts) }\end{array}$ & $\begin{array}{c}\bar{E} \\
(\mathrm{GPa})\end{array}$ & $\begin{array}{c}\mathrm{E}_{\mathrm{L}} \\
(\mathrm{GPa})\end{array}$ & $\begin{array}{c}\mathrm{E}_{\mathrm{T}} \\
(\mathrm{GPa})\end{array}$ & $\begin{array}{c}\mathrm{E}_{\mathrm{R}} \\
(\mathrm{GPa})\end{array}$ & $\frac{\bar{E}}{E_{L}} * 10$ & $\frac{\bar{E}}{E_{T}}$ & $\frac{\bar{E}}{E_{R}}$ & $\begin{array}{c}\mathrm{V} \\
\left(m m^{3}\right)\end{array}$ & $\begin{array}{c}\mathrm{V}^{\prime} \\
\left(\mathrm{mm}^{3}\right)\end{array}$ & $\frac{\varepsilon=\mathrm{V} * \mathrm{~N}}{\mathrm{~V}^{\prime}}$ \\
\hline 1 & 0.73 & 6.800 & 0.258 & 0.53 & 1 & 2.92 & 1.3 & 6.28 & 2512 & 0.0025 \\
\hline 5 & 0.62 & 6.800 & 0.258 & 0.53 & 0.911 & 2.48 & 1.14 & 31.4 & 2512 & 0.0125 \\
\hline 15 & 0.367 & 6.800 & 0.258 & 0.53 & 0.52 & 1.44 & 0.67 & 94.2 & 2512 & 0.0375 \\
\hline 50 & 0.022 & 6.800 & 0.258 & 0.53 & 0.072 & 0.0916 & 0.0432 & 314 & 2512 & 0.0125 \\
\hline 100 & 0.0042 & 6.800 & 0.258 & 0.53 & 0.066 & 0.0168 & 0.0079 & 628 & 2512 & 0.25 \\
\hline 167 & 0.003 & 6.800 & 0.258 & 0.53 & 0.0048 & 0.0134 & 0.0063 & 1048 & 2512 & 0.451 \\
\hline 187 & 0.0030 & 6.800 & 0.258 & 0.53 & 0.0044 & 0.0128 & 0.006 & 1174 & 2512 & 0.5 (fail) \\
\hline
\end{tabular}

In Table 3, $\mathrm{V}$ and $\mathrm{V}^{\prime}$ stand for undamaged, damaged zone volume, respectively. The obtained numerical results showed that, by increasing the number of microcracks, mechanical properties of damaged zone are decreased (see Figs. 8-10).

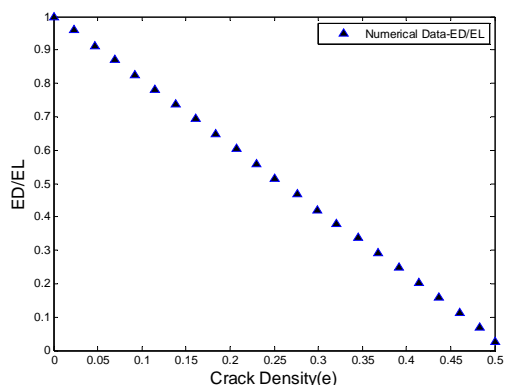

Fig. 8. Effective elasticity modulus versus crack density parameter

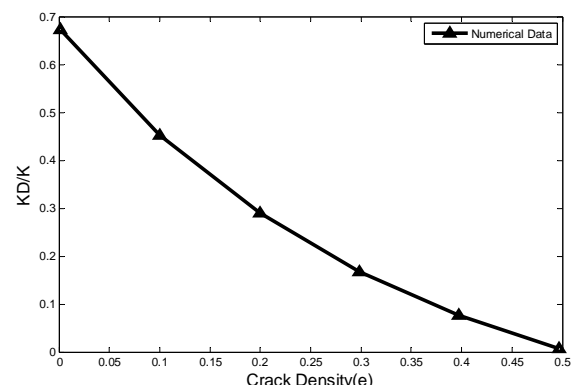

Fig. 9. Effective bulk modulus versus crack density parameter

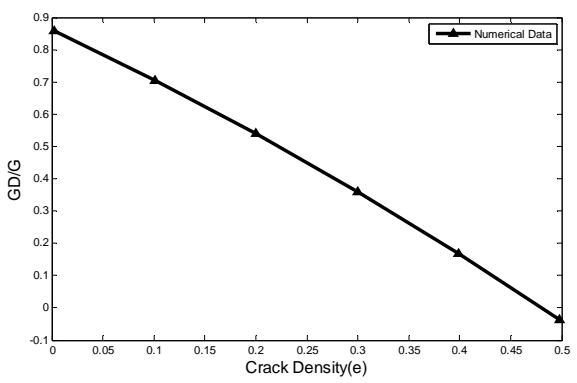

Fig.10. Effective shear modulus versus crack density parameter 


\subsection{Experimental Tests}

Western white pine was considered for experimental analysis. Microcracks were modeled as circular $(D=1 \mathrm{~mm})$. For creation of microcracks, a precision drill/grinder (FBS 240/E Proxxon) was used (Fig.11).

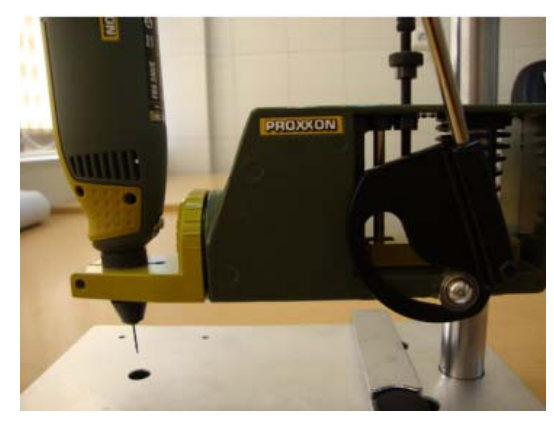

Fig. 11. Precision drill/grinder FBS 240/E Proxxon used in this study

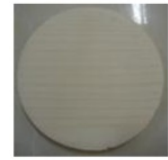

(0)

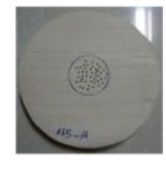

(45)

Fig. 12. increasing the number of microcrack in FPZ

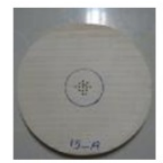

(15)

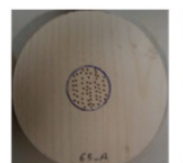

(65)

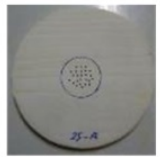

(25)

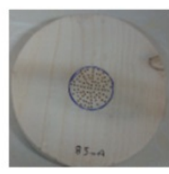

(85)

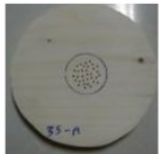

(35)

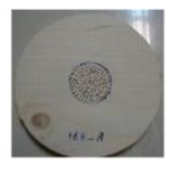

$(168)$

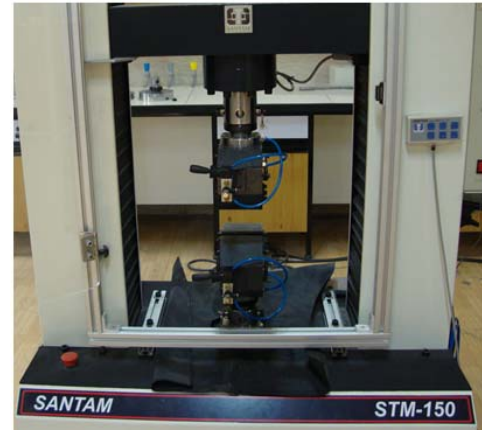

Fig. 13. Universal test machine used in present study

However, in order to measure the mechanical properties and critical crack density, first 1 to 200 Microcracks were created in previous condition, respectively (Fig.12). Then each specimen (1-200), was loaded by rate of $1 \mathrm{~mm} / \mathrm{min}$ using a tension test machine shown in Fig.13. Eventually, extremes of strain and stress were obtained for each test sample. Thus, effective mechanical properties of damaged zone were evaluated in course of increasing the number of microcracks. For each ascending in microcrack, effective mechanical property of damaged zone versus microcrack density was calculated using experimental data. In this method, after polishing and drilling of specimen, the damage zone was observed using a microscope (10x to 100x magnification) as it is shown in Fig.14 (a-d). The results obviously indicated that although every defect has nearly smooth surface, (due to the very small discordant and defect) it could be behave as microcrack.

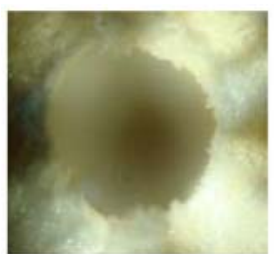

(a)

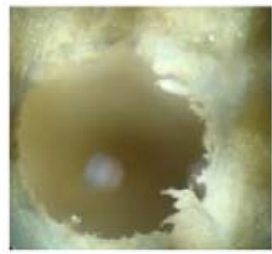

(c)

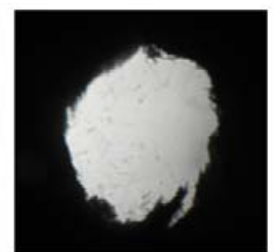

(b)

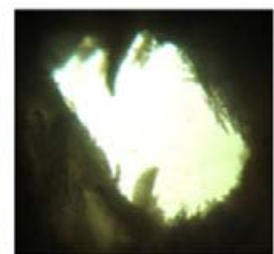

(d)

Fig.14. Defect in damage zone, (a), (b), (c) and (d) were investigated by 10x, 20x, 50x and 100x, respectively

Therefore, by increasing the crack density, it is expected that mechanical behavior of damaged zone should be decreased but not similar to the numerical method (i.e. the defects cannot be propagate easily). In present research, deviations, inferred from natural tiny cracks (that distributed in wood), circularly artificial defects (that causes microcrack cannot propagated, properly), calibration of test fixture, tiny magnitude of discordant in Nano scale and other reasons. On the other hand, these deviations may effect on the propagation of crack and cause dilation in failure, means rate of propagation is low. 


\section{Results and discussion}

In this section, a comparison between numerical, experimental and analytical data is done. Since $K, E$ and $G$ (i.e. bulk, elasticity and shear modulus, respectively) represent the mechanical properties; the comparison was done among these results (Figs.15-17).

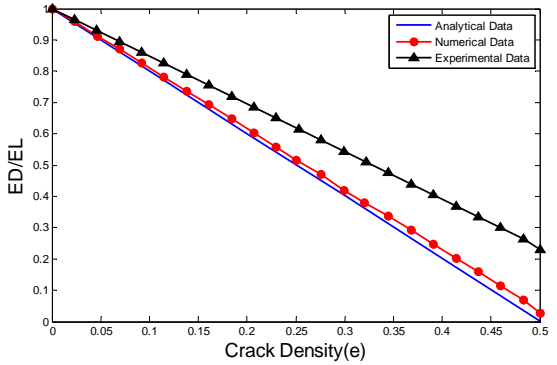

Fig. 15. Effective elasticity modulus versus crack density

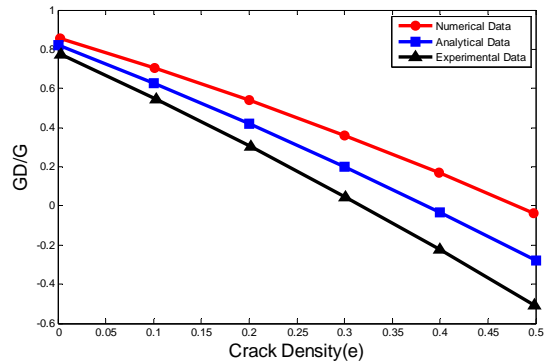

Fig. 16. Effective shear modulus versus crack density

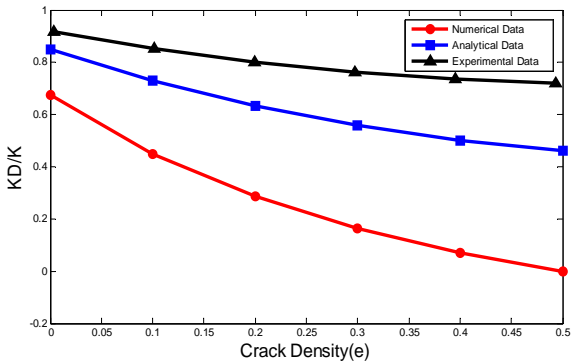

Fig. 17. Effective bulk modulus versus crack density

The presented method for every microcrack density has been compared with existing analytical and experimental criteria for fracture in wood, which indicates a deviation in results. As it mentioned, there are several factors that can affect the mechanical properties. The deviation increases with increasing the microcracks density that inferred from several factors e.g. microcracks geometry (which in numerical analysis for simplifying was modeled as a circle), types of elements at crack tip vicinity (which here was modeled by triangular elements), type of shape function and partition, natural tiny crack in wood and etc. Despite of this digression, present approach, can accurately simulate the orthotropic fracture process zone. It means that if the method applies for orthotropic materials with low natural tiny crack, the results would be improved. Eventually, a polynomial function in fiber direction was calculated that correlates the elasticity modulus in the course of microcrack density parameters (Eq. 9).

$\frac{E D}{E L}==A * \exp (B * \varepsilon)+C * \exp (D * \varepsilon)$

where A, B, C and D depends on boundary condition (loading and geometry). It has to be mentioned that, the polynomial equation was obtained from curve fitting of FEM data.

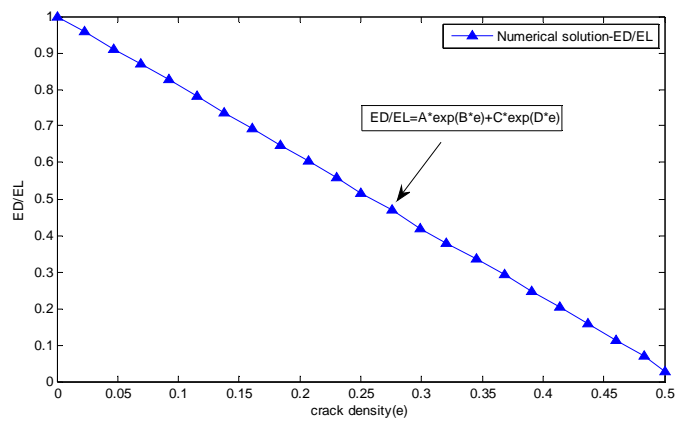

Fig.18. Polynominal function of Effective elasticity modulus versus crack density Parameters

\section{Conclusion}

In present research, a new approach referred to "damaged zone simulation (DZS)" was proposed for investigation of mechanical properties of the crack tip local damage zone based on numerical and experimental tests. This method consists of fracture analysis of orthotropic materials (wood was tested as a case study) with arbitrarily oriented microcrack. Take in to account that microcracks, were distributed in process zone, randomly. For simplification the defects were modeled as circle. Three 
mechanical properties $K, G$ and $E$ (bulk, shear and elasticity modulus) were evaluated and compared with existing analytical and experimental data. Moreover, the results indicated that if the microcrack density parameter is approximately about 0.50 , the failure would be happened in wood. It means that, critical microcrack density from numerical method obtained nearly 0.50 whereas the value of 0.56 was obtained from the analytical method. Eventually, comparison between numerical and experimental results with available analytical data showed the capabilities of the presented simulation.

\section{References}

Aliha, M. R. M., \& Ayatollahi, M. R. (2008). On mixed-mode I/II crack growth in dental resin materials. Scripta Materialia, 59(2), 258-261.

Aliha, M. R. M., Ayatollahi, M. R., \& Akbardoost, J. (2012). Typical upper bound-lower bound mixed mode fracture resistance envelopes for rock material. Rock mechanics and rock engineering, 45(1), 6574.

Aliha, M. R. M. (2013). Indirect tensile test assessments for rock materials using 3-D disc-type specimens. Arabian Journal of Geosciences, 1-10.

Ayatollahi, M. R., \& Aliha, M. R. M. (2007). Wide range data for crack tip parameters in two disc-type specimens under mixed mode loading. Computational materials science, 38(4), 660-670.

Barbero, E. J. (2007). Finite element analysis of composite materials. CRC press.

Boström, L. (1992). Method for determination of the sfrequuentlying behaviour of wood and the applicability of a nonlinear fracture mechanics model (Doctoral dissertation, Lund University).

Budiansky, B., \& O'connell, R. J. (1976). Elastic moduli of a cracked solid. International Journal of Solids and Structures, 12(2), 81-97.

Chow, C. L., \& Woo, C. W. (1979). Orthotropic and mixed mode fracture in wood. In Proceedings of the 1st international conference of wood fracture. Vancouver (pp. 39-52).

GohariAnaraki A. \& Fakoor, M. (2010). Mixed mode fracture criterion for wood based on a reinforcement micro-crack damage model. Materials Science and Engineering: A, 527(27), 7184-7191.

Harris, C. E., \& Morris, D. H. (1984). Fracture Behavior of Thick, Laminated Graphite/Epoxy Composites. VIRGINIA POLYTECHNIC INST AND STATE UNIV BLACKSBURG DEPT OF ENGINEERING SCIEN CE AND MECHANICS.

Hillerborg, A. (1991). Application of the fictitious crack model to different types of materials.International Journal of Fracture, 51(2), 95-102.

Hutchinson, J. W., \& Suo, Z. (1992). Mixed mode cracking in layered materials. Advances in applied mechanics, 29(63), 191.

Irwin, G. R. (1957). Analysis of stresses and strains near the end of a crack traversing a plate. J. appl. Mech.

Jernkvist, L. O. (2001). Fracture of wood under mixed mode loading: I. Derivation of fracture criteria. Engineering Fracture Mechanics, 68(5), 549-563.

Novozhilov, V. V. (1969). On a necessary and sufficient criterion for brittle strength: PMM vol. 33, n 2 , 1969, pp. 212-222. Journal of Applied Mathematics and Mechanics, 33(2), 201-210.

Poe Jr, C. C. (1983).A unifying strain criterion for fracture of fibrous composite laminates. Engineering Fracture Mechanics, 17(2), 153-171.

Sih, G. C., Paris, P. C., \& Irwin, G. R. (1965). On cracks in rectilinearly anisotropic bodies. International Journal of Fracture Mechanics, 1(3), 189-203.

Smith, I., \&Vasic, S. (2003). Fracture behaviour of softwood. Mechanics of materials, 35(8), 803-815.

USDA, Wood Handbook, Wood as an engineering material, Forest Products Laboratory, Forest Service, United States Department of Agriculture, US Government Printing Office, Washington, DC: USA, 1999.

Veselý, V., \& Frantík, P. (2014). An application for the fracture characterisation of quasi-brittle materials taking into account fracture process zone influence. Advances in Engineering Software, 72, 66-76.

Wu, E. M. (1967). Application of fracture mechanics to anisotropic plates. Journal of Applied Mechanics, 34(4), 967-974. 